Cadernos de Clio, Curitiba, v. 11, nº. 2, 2020

\title{
RESENHA DE TRAIGO UN PUEBLO EN MI VOZ: DIÁLOGO ENTRE A OBRA DE MERCEDES SOSA E OS TRABALHADORES RURAIS COM O FIM DA REVOLUCIÓN ARGENTINA ${ }^{1}$
}

PETROCELLI; TORO, 1973. Cuando tenga la tierra. In: SOSA, Mercedes. Traigo un pueblo en mi voz. Buenos Aires: Philips, 1973.

RITRO; VALLEJO, 1973. Hermano, dame tu mano. In: SOSA, Mercedes. Traigo un pueblo en mi voz. Buenos Aires: Philips, 1973.

GÓMEZ; ISELLA, 1973. Triunfo agrario. In: SOSA, Mercedes. Traigo un pueblo en mi voz. Buenos Aires: Philips, 1973.

Eduardo Veiga Nogueira ${ }^{2}$

Resgatar os conflitos sociais argentinos de meados do século XX, os marginalizados da América Latina e a arte militante e popular aliada à tradição folclórica, pode significar resgatar a vida de Mercedes Sosa. Ao longo de seus 50 anos de atividade e engajamento político, Sosa mostrou a intrínseca relação de sua obra com a realidade. Firmando-se como artista nas décadas de 1950-1960, La Negra (como Sosa também era chamada) foi uma das principais representantes da Nueva Canción, movimento musical latino, de perspectivas políticas e que deixou profundas marcas em todo o

\footnotetext{
${ }^{1}$ Agradecimentos a Professora e Mestre em Educação, Regiane Pinheiro Dionisio Porrua, que auxiliou nas traduções de canções, o que possibilitou maior compreensão sobre as letras da obra analisada.

2 Graduando em Comunicação Social, curso de Jornalismo, pela Pontifícia Universidade Católica do Paraná (PUCPR). Email: duxonthetable@gmail.com. Endereço para o currículo Lattes: http://lattes.cnpq.br/2435788936582123.
} 
continente. As músicas interpretadas por Sosa causaram uma ruptura com os paradigmas da música folclórica argentina, pois, ao mesmo tempo que deixavam de lado certo padrão musical, buscavam reinterpretações críticas da realidade (WOZNIAK-GIMÉNEZ, 2019). O engajamento encontrado na obra de Mercedes Sosa - e de outros artistas argentinos que confrontavam a canção folclórica - está diretamente ligado às marcas deixadas pela política argentina do período mencionado: o fim do governo de Juan Domingo Perón (1946-1955), que diminuiu a participação popular na política nacional e aumentou a marginalização da classe trabalhadora; e a ascensão da ideologia liberal e desenvolvimentista do governo de Arturo Frondizi (1958-1963), alavancada pelo objetivo de expansão econômica e industrial (RIBEIRO, 2006). A efervescência social causada por esse período desembocará na “década militante”, intervalo de 1966-1975, na Argentina (MOLINERO, 2011). Dois acontecimentos de grande interesse para esta resenha percorrem a década militante: de um lado, o fortalecimento do engajamento de Mercedes Sosa com as causas populares, paralelo à sua projeção nacional e midiática em festivais de música popular (WOZNIAK-GIMÉNEZ, 2019); contraposto a isso, o recrudescimento das forças militares sobre o governo de Arturo Umberto Illia, trazendo, em 1966, Juan Carlos Onganía à Presidência como o primeiro presidente de um regime ditatorial, repressivo, antiperonista e neoliberal (intitulado Revolución Argentina) que duraria sete anos. A música de Mercedes Sosa deste período, portanto, pode se tornar valioso instrumento de análise e reflexão sobre a sociedade argentina da época. 
A presente resenha busca ser breve e de maneira alguma deseja compreender a militância de Mercedes Sosa em sua integridade. Pelo contrário, foca-se estritamente em uma das bandeiras recorrentemente levantadas na obra de Sosa: os direitos dos trabalhadores do campo. A intérprete trouxe, para suas canções, dentre outros, "trajetórias, trabalhos, esperanças e sofrimentos e possibilidades de luta de trabalhadores rurais" (WOZNIAK-GIMÉNEZ, 2019: n.p). Para analisar a relação da obra de Sosa com os campesinos, decide-se abordar seu álbum de 1973, Traigo un pueblo en mi voz. As letras presentes no álbum, algumas à frente analisadas, ganham em profundidade quando colocadas em vista do contexto político daquele ano: os militares optam por reestabelecer a democracia argentina, com eleições presidenciais que, apesar de excluírem a candidatura de Perón (que retorna ao país nesse mesmo ano, após um exílio na Espanha desde 1955), permitem a candidatura e sequente vitória do peronista Héctor Cámpora. À renúncia de Cámpora e de seu vice, ainda em 1973, são convocadas novas eleições presidenciais, permitindo o retorno de Juan Domingo Perón ao poder.

O fim do regime ditatorial é indispensável para o entendimento do que esse ano significou para os trabalhadores do campo. Na canção que abre Traigo un pueblo en mi voz, é possível encontrar essa relação. Escrita por Ariel Petrocelli e Daniel Toro, “Cuando tenga la tierra” invoca, em seu trecho inicial, o personagem literário Martín Fierro e três classes sociais representativas da luta pelos direitos sociais durante a Revolución 
Argentina: os professores, os trabalhadores e los hacheros, representando, neste caso, o trabalhador do campo.

Cuando tenga la tierra / Sembraré las palabras / Que mi padre Martín Fierro puso al viento / Cuando tenga la tierra / La tendrán los que luchan / Los maestros, los hacheros, los obreros $^{3}$ (PETROCELLI; TORO, 1973).

A luta dos trabalhadores rurais argentinos, referida na canção, joga luz sobre o conflito de interesses políticos e econômicos existente entre eles e os grandes proprietários de terra do país. Para contextualizar tal conflito, vale situar a Sociedad Rural Argentina (SRA), principal entidade de representação latifundiária do período. A SRA apoiou o golpe institucional da Revolución Argentina e, ao longo dos anos, estabeleceu uma relação ambígua com o regime. Se a entidade discordava de certas políticas de tributação e intervenção do estado adotadas para com a produção agrícola e pediam um processo de industrialização mais intenso no campo, por outro lado se alinhava ideologicamente aos ditadores e validava a permanência de um estado antidemocrático (GENTIL, 2016). O governo militar, com sua postura firmada no neoliberalismo, eliminava a possibilidade de políticas mais favoráveis aos trabalhadores rurais. Inclui-se a isso, sobretudo, a impossibilidade de uma reforma agrária no país, medo recorrente aos latifundiários no início da década de 1970, em decorrência do aumento de

\footnotetext{
3 "Quando eu tiver a terra / Semearei as palavras / Que meu pai Martin Fierro gritou ao vento / Quando eu tiver a terra / Tê-la-ão os que lutam / Os professores, os lenhadores, os trabalhadores".
} 
grupos e partidos políticos argentinos adeptos à reforma. Sobre esse medo, bem elucida Leandro Gomes Gentil, apresentando as diversas defesas feitas pela Sociedad Rural Argentina da liberdade individual e do direito à propriedade privada naquele período (GENTIL, 2016). A defesa da reforma agrária por partidos políticos somava-se ao contexto de altíssima concentração de terras e incontrolado êxodo rural que dominava a Argentina, como explicita Gentil (2016).

Nos anos 60, por exemplo, estudos apontavam que 50\% das terras estavam concentradas nas mãos de $1,5 \%$ da população, assim como $80 \%$ da população carecia de terras. Cinquenta famílias possuíam cerca de quatro milhões de hectares de terra; $2 \%$ dos pecuaristas possuíam $40 \%$ do gado argentino e, $5 \%$ da população possuíam $40 \%$ da riqueza nacional. Esses números, a SRA ignorava completamente (GENTIL, 2016: 93).

Ao cantar "cuando tenga la tierra, te lo juro, semilla, que la vida será un dulce racimo"4 (PETROCELLI; TORO, 1973), Mercedes Sosa clama por uma política rural voltada aos pequenos agricultores. Com esperança, a alegria desejada por Sosa poderia ser vislumbrada com o fim da Revolución Argentina.

A esperança aparece com veemência na figura artística de Sosa. A terceira canção do álbum é Hermano, dame tu mano, escrita por Ángel Ritro e César Vallejo, onde La Negra transcende os limites territoriais para abraçar a política agrária voltada aos trabalhadores rurais.

\footnotetext{
4 "Quando eu tiver a terra, eu te juro, semente, que a vida será um doce cacho".
} 
Hermano, dame tu mano vamos juntos a buscar / Una cosa pequeñita que se llama libertad / Esta es la hora primera, este es el justo lugar / Abre la puerta que afuera la tierra no aguanta más ${ }^{5}$ (RITRO; VALLEJO, 1973).

Com as insurreições populares que marcaram a passagem 1960-1970, conhecidas como "Puebladas" (1969-72), a atitude política de Mercedes Sosa, como revela Wozniak-Giménez (2019), dá destaque à perspectiva já apontada pela Nueva Canción Argentina em seu manifesto, Nuevo Cancionero, de 1963: "a utopia da unidade latino-americana como forma de luta contra o capitalismo e as opressões impetradas sobre os povos da região" (WOZNIAK-GIMÉNEZ, 2019: n.p). Isso permitiu que o canto de Sosa mobilizasse identidades e questões sociais mais abrangentes, entendendo a unidade latino-americana como instrumento de libertação. A partir dessa perspectiva, o entendimento e a defesa da terra em Hermano, dame tu mano ganha uma outra análise: o olhar sobre a terra não apenas como meio de reduzir as desigualdades econômicas e sociais, mas também como meio de resistência política democrática, transpondo ainda as barreiras geográficas. É traçada uma metáfora, onde os trabalhadores rurais representam a força popular argentina e latino-americana, de modo geral, enquanto a terra se torna a própria nação.

5 "Irmão me dê sua mão vamos juntos buscar / Uma coisa pequenina que se chama liberdade / Esta é a hora primeira, este é o lugar certo / Abre a porta que lá fora a terra já não aguenta mais". 
Mira adelante hermano es tu tierra la que espera / Sin distancias, ni fronteras que pongas alta la mano / Sin distancias, ni fronteras esta tierra es la que espera / El clamor americano levanten pronto la mano al señor de las cadenas ${ }^{6}$ (RITRO; VALLEJO, 1973).

Com a volta de eleições presidenciais e de um regime democrático, Mercedes Sosa impulsiona os argentinos a se unirem e lutarem por seu país: "Métale a la marcha, métale al tambor / Métale que traigo un pueblo en mi voz"7 (RITRO; VALLEJO, 1973).

Como citado anteriormente, o peronismo, seguido do próprio Perón, voltou ao governo com o fim da Revolución Argentina. Mesmo após 23 anos afastado da presidência, as marcas deixadas pelo nacional-populismo de Perón ainda o acompanhavam. Na lembrança dos trabalhadores do campo, o peronismo foi o regime que mais trouxe benefícios a eles. Tal afirmação justifica-se em decretos e leis estabelecidos pelo peronismo em favor de arrendatários, pequenos e médios agricultores (GENTIL, 2016). Em seu primeiro mandato, de 1946, Perón chegou à Presidência trazendo consigo, por exemplo, a herança do Decreto 14.001, de 1943, que possibilitou regras mais favoráveis aos arrendatários; bem como do Estatuto del Peón, uma tentativa do governo, em 1944, de levar melhores condições de vida aos trabalhadores (RIBEIRO, 2006). Tanto o Decreto

6 "Olhe para a frente adiante irmão é a sua terra que esperas / Bem perto e sem fronteiras que impeçam suas mãos / Bem perto e sem fronteiras é a terra que esperas / O clamor americano levantem logo a mão para o Senhor".

7 "Apresse a marcha, apresse o tambor / Apresse que trago um povo em minha voz". 
14.001 quanto a tentativa de elaboração do Estatuto del Peón foram durante o período em que Perón esteve à frente da Secretaria do Trabalho e Segurança Social no país. Perón e sua base entenderam, dentro desse contexto, que os trabalhadores rurais representavam uma base política, e, por isso, sinalizar mais direitos a essa parcela da população durante as eleições, inclusive com a reforma agrária, seria fundamental para alcançar a Presidência. Com a queda de Perón, em 1955, as políticas favoráveis aos trabalhadores do campo, como a garantia de estabilidade do arrendatário na terra em que trabalhava, garantida pela Lei de Arrendamentos e Parcerias, de 1948, foram todas revogadas por novos decretos (GENTIL, 2016). À prática do período peronista, soma-se a retórica de seu líder: "La tierra para quien la trabaja", famoso bordão da campanha de 1946.

É com aflição e angústia que Mercedes Sosa traz a memória peronista à tona com a canção Triunfo agrario, quinta faixa de Traigo un pueblo en mi voz, escrita por Armando Tejada Gómez e César Isella: “Éste es un triunfo, madre, pero sin triunfo / Nos duele hasta los huesos el latifundio / Ésta es la tierra, padre, que vos pisabas / todavía mi canto no la rescata"8 (GÓMEZ; ISELLA, 1973). A canção une o aspecto folclórico da arte de Sosa com o pensamento político, pois, ao mesmo tempo que dialoga com seus antepassados de um período pré-colonização, onde a prática latifundiária não existia entre o povo argentino, também fala diretamente com seus pais, peronistas e trabalhadores das lavouras de cana na década de

\footnotetext{
8 "Este é um triunfo, mãe, mas sem triunfo / Dói até nos ossos o latifúndio / Esta é a terra, pai, que você pisava / Mas meu canto não a resgata".
} 
1940. A militância de Sosa luta para que o progresso de uma nova era política não seja desfeito, tal qual os períodos que regrediram quanto aos direitos dos trabalhadores do campo instituídos pelo peronismo. Triunfo agrario revela que, apesar da luta popular, os problemas sociais ainda se colocam à mercê de um jogo de sorte, e a isso resta a esperança, tão esboçada no álbum de Sosa: "Hay que dar vuelta el viento / Como la taba / El que no cambia todo, no cambia nada" (GÓMEZ; ISELLA, 1973).

Traigo un pueblo en mi voz é uma obra paradigmática na discografia de La Negra. As canções apresentam um íntimo diálogo com o contexto da época e, conforme analisado na presente resenha, se entrelaçam com a luta dos campesinos em diversos sentidos. Os anseios do campo são postos sob a ebulição social de um ano que marca o fim do regime militar, o respiro democrático e o retorno do peronismo. Um olhar sensível sobre a obra de Mercedes Sosa contribui para o desenvolvimento de uma compreensão crítica acerca do período.

\section{Referências}

GENTIL, Leandro Gomes. O quartel e a fazenda: entidades de proprietários rurais frente aos regimes militares no Brasil e Argentina (1964-1983). 2016. 150 f. Dissertação (Mestrado) - Curso de História, Universidade Federal do Estado do Rio de Janeiro, Rio de Janeiro, 2016.

MOLINERO, Carlos D. Militancia de la canción. Política en el canto folklórico de la Argentina (1944-1975). In: WOZNIAK-GIMÉNEZ, Andrea Beatriz. Música popular e engajamento nos anos 60: cultura política nas

\footnotetext{
9 "Há um jogo de sorte / Como no jogo da taba / O que não muda tudo, não muda nada".
} 
trajetórias artísticas de Violeta Parra, Mercedes Sosa e Elis Regina. Escritas, Palmas, v. 6, n. 1, p. 66-83, 2014.

RIBEIRO, Vanderlei Vazelesk. A roça y la campana: a questão agrária sob o varguismo e o peronismo em perspectiva comparada. 2006. 249 f. Tese (Doutorado) - Curso de História, Universidade Federal Fluminense, Niterói, 2006.

WOZNIAK-GIMÉNEZ, Andrea Beatriz. Canto engajado em tempos autoritários: Mercedes Sosa e Elis Regina. In: SIMPÓSIO NACIONAL DE HISTÓRIA: HISTÓRIA E O FUTURO DA EDUCAÇÃO NO BRASIL, XXX, 2019, Recife. Anais... Recife: ANPUH, 2019.

Recebido em: 05/03/2021

Aceito em: 24/05/2021 